\title{
Sosialisasi Dampak Lingkungan Terhadap Penularan TB dan Filariasis di Negeri Hatuhenu Kecamatan Amahai Kabupaten Maluku Tengah
}

\author{
Gracia V. Souisa', Zukiflin P. Vauza ${ }^{2}$ \\ souisagracia@gmail.com \\ Program Studi Kesehatan Masyarakat \\ Fakultas Kesehatan \\ Universitas Kristen Indonesia Maluku
}

\begin{abstract}
Hatuhenu Village, Amahai Sub-district, Central Maluku District, based on interviews with health officials and the government of the village, have various health problems such as clean and healthy living behavior, environmental sanitation problems that have an impact on the emergence of environment-based diseases such as tuberculosis, filariasis and malaria. To solve the above health problems, the lecturers and students of the Public Health Majors in collaboration with health officials, the government of Hatahenu and church assemblies Hatuhenu are conducting counseling on "Environmental Impacts on TB and Filariasis Transmission in Hatuhenu Village" and public awareness to improve hygienic and clean living behavior, improve environmental sanitation and preventive behavior of $\mathrm{TB}$ and filariasis transmission. The results of the service show that the community, the Government of Hatuhenu, the Head of the Assembly of the Church and the health staff of the Public Health Center Hatuhenu Village responded positively and were greatly helped by the socialization activities in the effort to increase the knowledge of the community and the mass treatment that has been done.
\end{abstract}

Keywords: Environment, Counseling, Disease transmission

\begin{abstract}
Abstrak: Negeri Hatuhenu, Kecamatan Amahai, Kabupaten Maluku Tengah, berdasarkan hasil wawancara dengan petugas kesehatan dan pemerintah negeri, memiliki berbagai permasalahan kesehatan antara lain perilaku hidup bersih dan sehat, masalah sanitasi lingkungan yang berdampak pada munculnya penyakit berbasis lingkungan seperti TB, Filariasis dan Malaria. Untuk memecahkan berbagai masalah kesehatan di atas maka dosen dan mahasiswa Program Studi Kesmas bekerja sama dengan petugas kesehatan, pemerintah Negeri Hatuhenu dan Jemaat Hatuhenu melakukan penyuluhan tentang "Dampak Lingkungan Terhadap Penularan TB dan Filariasis di Negeri Hatuhenu Kecamatan Amahai Kabupaten Maluku Tengah" sehingga dapat meningkatkan pengetahuan dan kesadaran masyarakat untuk meningkatkan perilaku hidup bersih dan sehat, meningkatkan sanitasi lingkungan serta perilaku pencegahan penularan TB dan Filariasis. Hasil pengabdian menunjukan bahwa masyarakat, Pemerintah Negeri Hatuhenu, Ketua Majelis Jemaat dan perangkat pelayan serta petugas kesehatan puskesmas dan poskesdes Negeri Hatuhenu memberikan respon positif dan sangat terbantu dengan kegiatan sosialisasi dalam upaya peningkatan pengetahuan masyarakat dan pengobatan massal yang telah terlaksana.
\end{abstract}

Kata Kunci : Lingkungan, Penyuluhan, Penularan penyakit 


\section{ANALISIS SITUASI}

Lingkungan memiliki peranan yang besar dalam mempengaruhi derajat kesehatan masyarakat. Derajat kesehatan masyarakat dapat ditingkatkan jika terjadi peningkatan kondisi lingkungan. Peningkatan kondisi lingkungan sebagai pencegahan berbagai penyakit menular, penting dimulai dengan meningkatkan pengetahuan dan kesadaran masyarakat tentang berbagai faktor lingkungan yang mendukung penularan penyakit. Salah satu upaya meningkatkan pengetahuan masyarakat adalah melalui penyuluhan dan sosialisasi. Dengan pengetahuan yang memadai, masyarakat dapat diberdayakan sehingga mandiri dalam mengelola lingkungan dan meningkatkan derajat kesehatannya.

Memberdayakan keluarga dan masyarakat bukan hal yang mudah. Diperlukan pendampingan terus - menerus dan konsisten sehingga keluarga dan masyarakat secara terus -menerus didorong untuk berperilaku sehat serta memperbaiki lingkungan agar lebih sehat pula. Untuk mewujudkan tercapainya indikator utama dalam pembangunan kesehatan indonesia yakni lingkungan sehat, berperilaku sehat dan terjangkauan oleh pelayanan kesehatan yang profesional maka salah satu program utama untuk mencapai perilaku sehat bagi semua penduduk indonesia adalah program promosi kesehatan. Tatanan keluarga atau rumah tangga dalam mewujudkan perilaku sehat adalah merupakan pencerminan perilaku masyarakat. Pengetahuan sebagai parameter keadaan sosial dapat sangat menentukan keadaan kesehatan masyarakat. Masyarakat dapat terhindar dari penyakit asalkan pengetahuannya dapat ditingkatkan sehingga perilaku/ keadaan sosialnya sehat (Soemirat, 2011).

Negeri Hatuhenu, Kecamatan Amahai, Kabupaten Maluku Tengah sebagai lokasi kegiatan pengabdian kepada masyarakat memiliki berbagai permasalahan kesehatan antara lain kurangnya perilaku hidup bersih dan sehat, masalah sanitasi lingkungan dan kurangnya kesadaran masyarakat untuk mencegah penularan TB dan Filariasis. Berbagai permasalahan kesehatan yang ada di Negeri Hatuhenu, dapat dipengaruhi oleh kurangnya pengetahuan masyarakat tentang dampak lingkungan terhadap penularan penyakit. Selain kurangnya pengetahuan, menurut data BPS tahun 2017, Negeri Hatuhenu termasuk dalam 2 negeri dari 15 negeri di Kecamatan Amahai yang tergolong sangat miskin. Negeri Hatuhenu secara geografis berada di dalam kawasan hutan, sehingga potensial memiliki vector seperti nyamuk yang memindahkan agent penyakit seperti plasmodium, filaria dan lainnya. Jumlah penduduk di Negeri Hatuhenu sebanyak 440 orang, dengan jumlah anak SD sebagai populasi yang 


\section{Gracia V. Souisa ${ }^{1}$, Zukiflin P. Vauza ${ }^{2}$}

rentan sebanyak 109 orang. Negeri Hatuhenu memiliki 1 Poskesdes dengan 1 tenaga kesehatan yaitu bidan desa.

Hasil wawancara dengan petugas kesehatan di Poskesdes Hatuhenu, beberapa penyakit diderita masyarakat antara lain ISPA, Malaria, TB, Filariasis dan penyakit tidak menular lainnya seperti hipertensi, asam urat dan lainnya. Berdasarkan keterangan dari petugas kesehatan, ada masyarakat yang tidak mau mengkonsumsi obat anti-filaria dan DOTS untuk TB. Hasil observasi menunjukan bahwa sanitasi lingkungan di Negeri Hatuhenu masih perlu ditingkatkan oleh masyarakat diantaranya pengolahan sampah rumah tangga sehingga tidak menjadi tempat potensial adanya vector penyakit. Tujuan kegiatan ini dilakukan adalah untuk

1. Melakukan edukasi kepada masyarakat sehingga sadar dan meningkatkan perilaku hidup bersih dan sehat, serta meningkatkan sanitasi lingkungan

2. Melakukan upaya pencegahan penyakit menular akibat perilaku hidup sehat yang masih rendah

3. Meningkatkan cakupan pelayanan indikator PHBS seperti pengolahan air minum, akses terhadap sarana pembuangan akhir (jamban sehat), peningkatan personal higine bagi anggota rumah tangga seperti gerakan cuci tangan bersih bagi anak dan pengolahan sampah rumah tangga oleh masyarakat

Menurut Bloom, ada 4 peranan lingkungan dalam menyebabkan gangguan kesehatan yaitu reservoir sebagai tempat berkembang biaknya bibit penyakit, sebagai agent (penyebab penyakit), sebagai medium transmisi (perantara agent), dan Vektor. Aspek lingkungan yang penting diperhatikan untuk meningkatkan derajat kesehatan masyarakat Negeri Hatuhenu dan mencegah penyakit berbasis lingkungan seperti TB, filariasis dan malaria antara lain faktor lingkungan dalam rumah dan luar rumah, pembuangan air limbah serta pengolahan sampah rumah tangga.

\section{SOLUSI DAN TARGET}

Solusi yang ditawarkan untuk mengatasi permasalahan mitra adalah meningkatkan pengetahuan melalui penyuluhan/ sosialisasi tentang perilaku hidup bersih dan sehat, sanitasi lingkungan, kesadaran masyarakat untuk mencegah penularan TB dan Filariasis. Dengan meningkatnya pengetahuan dan pemahaman masyarakat akan pentingnya hidup bersih dan sehat, serta sanitasi lingkungan diharapkan dapat mendorong kesadaran masyarakat untuk membiasakan pola hidup bersih dan sehat serta pencegahan penularan TB dan Filariasis. 
Gracia V. Souisa ${ }^{1}$, Zukiflin P. Vauza ${ }^{2}$

Kegiatan pengabdian kepada masyarakat dilaksanakan pada Senin, 23 Oktober 2017 di Gedung Gereja Negeri Hatuhenu. Adapun kegiatan yang dilaksanakan meliputi :

\begin{tabular}{|l|l|l|l|l|}
\hline No & \multicolumn{1}{|c|}{ Kegiatan } & \multicolumn{1}{c|}{ Metode } & \multicolumn{1}{c|}{ Target } & \multicolumn{1}{|c|}{ Partisipasi Mitra } \\
\hline 1 & $\begin{array}{l}\text { Memberikan } \\
\text { pemahaman tentang } \\
\text { dampak lingkungan } \\
\text { bagi penularan Filariasi } \\
\text { dan TB }\end{array}$ & Penyuluhan & $\begin{array}{l}\text { Meningkatnya } \\
\text { pengetahuan } \\
\text { Masyarakat } \\
\text { Hatuhenu }\end{array}$ & $\begin{array}{l}\text { Menyediakan } \\
\text { tempat, ikut } \\
\text { kegiatan, aktif } \\
\text { dalam diskusi }\end{array}$ \\
\hline 2 & Pengobatan massal & $\begin{array}{l}\text { Pemeriksaan dan } \\
\text { pembagian obat } \\
\text { oleh petugas } \\
\text { kesehatan }\end{array}$ & $\begin{array}{l}\text { Masyarakat } \\
\text { Hatuhenu } \\
\text { mendapat } \\
\text { layanan } \\
\text { kesehatan }\end{array}$ & $\begin{array}{l}\text { Menyediakan } \\
\text { tempat, mengikuti } \\
\text { kegiatan }\end{array}$ \\
\hline
\end{tabular}

Target luaran dari pengabdian ini adalah publikasi ilmiah pada jurnal dan pengayaan bahan ajar.

\section{PELAKSANAAN}

Kegiatan yang dilaksanakan dalam kegiatan pengabdian adalah :

1. Memberikan pengetahuan dan pemahaman melalui penyuluhan/ sosialisasi tentang dampak lingkungan terhadap penularan TB dan Filariasis melalui penyuluhan masyarakat Negeri Hatuhenu.

2. Memberikan pengobatan massal melalui kerjasama dengan petugas Poskesdes Negeri Hatuhenu (Puskesmas Latwaru)
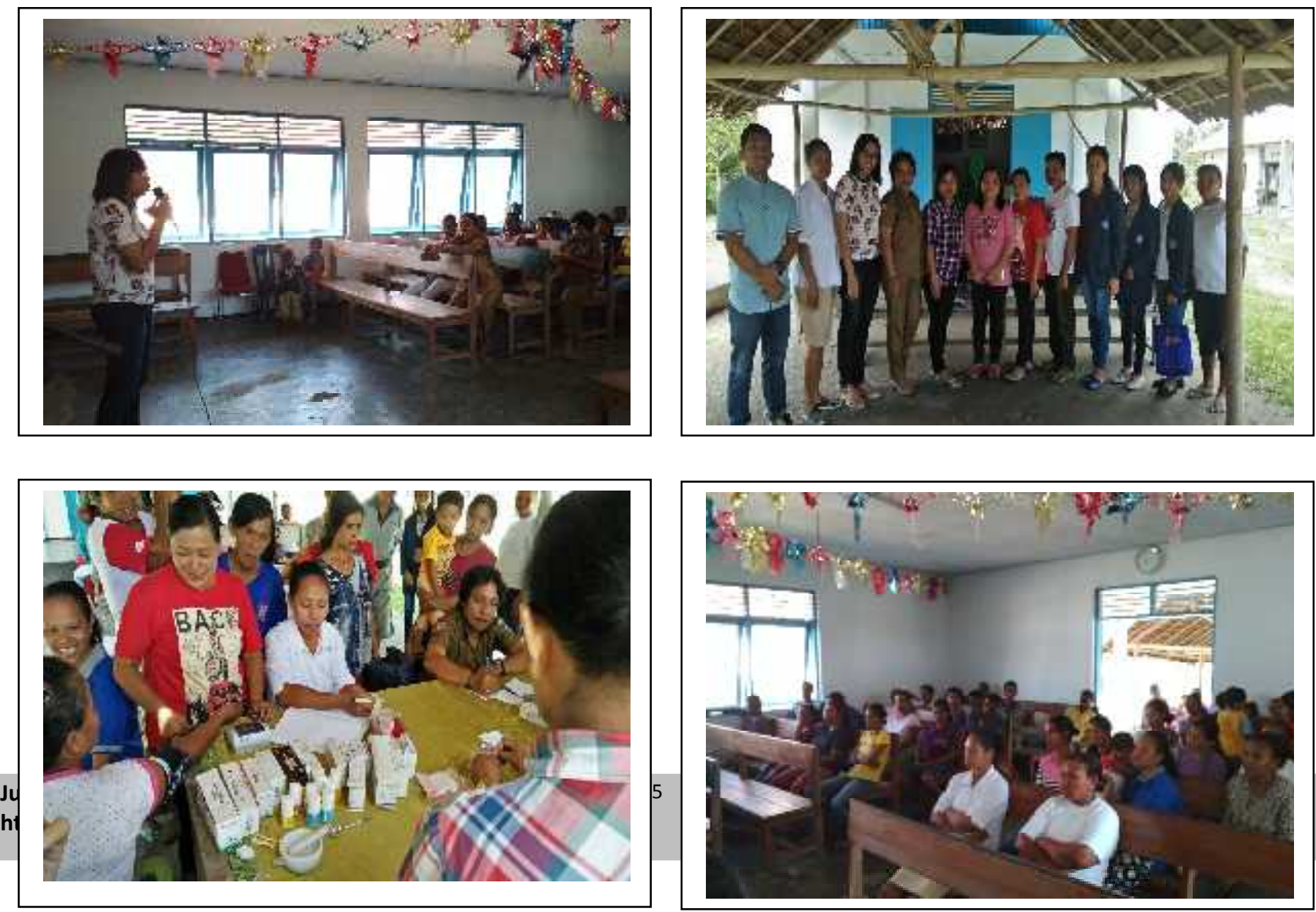


\section{HASIL DAN LUARAN}

Kegiatan pengabdian masyarakat dilakukan dalam bentuk sosialisasi/ penyuluhan dengan tema "Dampak Lingkungan Terhadap Penularan TB dan Filariasis di Negeri Hatuhenu, Kecamatan Amahai, Kabupaten Maluku Tengah”. Penyuluhan ditujukan kepada seluruh kepala keluarga di Negeri Hatuhenu. Selain penyuluhan, kegiatan pengabdian kepada masyarakat juga melibatkan kader poskesdes dan petugas kesehatan dalam aksi pengobatan massal bagi masyarakat Negeri Hatuhenu.

Kegiatan sosialisasi dan pengobatan massal dilakukan pada hari Senin, 23 Oktober 2017, di gedung Gereja Jemaat Hatuhenu dan terlaksana dalam 2 tahap yaitu pukul 10.00 WIT untuk kegiatan penyuluhan/ sosialisasi dan pukul 12.00 WIT dilaksanakan kegiatan pengobatan massal. Untuk memudahkan pemahaman masyarakat Hatuhenu akan pentingnya dampak lingkungan terhadap penularan penyakit, penyuluhan dibantu dengan tampilan slide melalui LCD sehingga meningkatkan antusiasme masyarakat untuk menyimak setiap materi yang ada. Masyarakat tertarik dengan penyuluhan terkait dampak lingkungan dalam penularan penyakit yang diaktualisasikan dalam pertanyaan terkait pengolahan sampah, perilaku minimisasi sampah dan tindakan 3R (Reduce, reuse, recycle).

Kegiatan sosialisasi dan pengobatan massal di Negeri Hatuhenu terlaksana atas kerjasama dosen program studi kesehatan masyarakat, pemerintah negeri hatuhenu, puskesmas dan poskesdes negeri hatuhenu serta jemaat GPM Negeri Hatuhenu. Kegiatan ini dilakukan karena adanya beberapa penyakit menular yang pencegahannya penting dilakukan dengan meningkatkan pengetahuan masyarakat. Beberapa penyakit menular di negeri hatuhenu, berdasarkan hasil wawancara dengan petugas kesehatan adalah TB dan Filariasis. Masyarakat yang mengikuti kegiatan sosialisasi sejumlah 53 orang terdiri dari perangkat desa, kader puskesmas, perangkat pelayan gereja dan masyarakat lainnya yang berkesempatan hadir. Masyarakat antusias untuk mengikuti kegiatan sosialisasi yang diresponi dengan sejumlah pertanyaan, seperti :

a. Bagaimana cara pengolahan sampah plastic (3R)?

b. Bagaimana penularan TB dan filariasis?

c. Bagaimana pencegahan TB dan filariasis? 


\section{Gracia V. Souisa ${ }^{1}$, Zukiflin P. Vauza ${ }^{2}$}

d. Apakah diperbolehkan menggunakan kembali botol plastic sekali pakai?

Faktor lingkungan sangat berpengaruh terhadap kepadatan vector penular penyakit, sehingga pengendalian faktor lingkungan masih sangat diperlukan antara lain pembersihan saluran pembuangan air, pengaliran air yang tergenang, pemberantasan tempat peristirahatan nyamuk melalui pembersihan semak - semak dan kandang ternak. Beberapa faktor lingkungan rumah yang berhubungan dengan kejadian penularan TB paru adalah kepadatan hunian, pencahayaan, kelembaban, luas ventilasi, jenis lantai, bahan bakar dan lainnya. Penularan TB pada rumah yang tidak dimasuki sinar matahari lebih besar dibandingkan dengan yang dimasuki matahari. Strategi nasional program pengendalian TB nasional tahun 2015 - 2019 mencantumkan bahwa tatalaksana TB paripurna dapat dilakukan melalui promosi tuberculosis, pencegahan, penemuan pasien, pengobatan pasien dan rehabilitasi pasien tuberculosis.

Dalam sosialisasi juga dihimbau kepada masyarakat untuk tidak takut mengkonsumsi obat anti-filaria dan obat TB. Penelitian yang dilakukan oleh Astuti dkk (2013) menunjukan bahwa dukungan kader, tokoh masyarakat dan petugas kesehatan sangat dibutuhkan untuk eliminasi filariasis dalam hal penyebaran informasi atau pengetahuan kepada masyarakat. Pengetahuan, sikap, keyakinan, takut reaksi/ efek, sosialisasi berpengaruh terhadap ketidakpatuhan minum obat. Selanjutnya masyarakat diarahkan untuk melakukan pemeriksaan kesehatan dan pemberian obat dari petugas kesehatan. Masyarakat yang terlibat dalam pengobatan massal lebih banyak dibandingkan dengan yang terlibat dalam kegiatan sosialisasi, dikarenakan sebagian masyarakat yang bermata pencaharian sebagai petani yang bekerja ketika sosialisasi dilakukan. Hasil pemeriksaan kesehatan didapatkan banyak masyarakat yang mengalami hipertensi, asam urat, malaria, flu dan batuk.

Pemerintah Negeri Hatuhenu, Ketua Majelis Jemaat dan perangkat pelayan serta petugas kesehatan puskesmas dan poskesdes Negeri Hatuhenu memberikan respon positif dan sangat terbantu dengan kegiatan sosialisasi dan pengobatan massal yang telah terlaksana. Akhir dari kegiatan, memberikan apresiasi dan penyampaian terima kasih serta foto bersama dengan pemerintah negeri, ketua majelis jemaat, petugas kesehatan dan para kader.

\section{KESIMPULAN}

Sosialisasi/ penyuluhan dampak lingkungan terhadap penularan filariasis dan TB serta pengobatan massal di Negeri Hatuhenu, Kecamatan Amahai, Kabupaten Maluku Tengah terlaksana dengan baik. Sosialisasi di respon positif oleh masyarakat Negeri Hatuhenu, dan 


\section{Gracia V. Souisa ${ }^{1}$, Zukiflin P. Vauza ${ }^{2}$}

membantu meningkatkan pengetahuan masyarakat tentang dampak lingkungan terhadap penularan filariasis dan TB.

\section{DAFTAR PUSTAKA}

Astuti, P.E, Ipa M, Wahono T, Ruliansyah A. 2014. Analisis Perilaku Masyarakat Terhadap Kepatuhan Minum Obat Filariasis di Tiga Desa Kecamatan Majalaya Kabupaten Bandung, Tahun 2013. Media Litbangkes, Vol 24 No 4: 199-208

Kementerian Kesehatan RI. 2014. Pedoman Nasional Pengendalian Tuberkulosis, Indonesia Bebas Tuberkulosis. Jakarta: KemenkesRI.

Kementerian Perencanaan Pembangunan Nasional/ badan perencanaan Pembangunan Nasional (BAPPENAS). 2010. Peta jalan percepatan pencapaian Tujuan Pembangunan Millenium di Indonesia. Jakarta: BAPPENAS

Musadad Anwar. 2006. Hubungan Faktor Lingkungan Rumah dengan Penularan TB Paru Kontak Serumah. Ekologi Kesehatan, Vol 5 No 3: 486-496

Sugiyanto. 2012. Analisis Faktor - Faktor yang Berhubungan dengan Ketidakpatuhan Minum Obat Filariasis pada Kegiatan Pengobatan Massal Tahun 2010 di Wilayah Kerja Puskesmas Soreang Kabupaten Bandung. 2-Trik: Tunas - Tunas Riset Kesehatan. Volume II No 1:1-8

Soemirat Juli. 2011. Kesehatan Lingkungan. Jogjakarta:UGM Press

Soekidjo Notoatmotdjo. 2010. Ilmu Perilaku Kesehatan. Jakarta: Rineka Cipta

Widoyono. 2008. Penyakit Tropis epidemiologi, penularan, pencegahan dan pemberantasan. Semarang: Erlangga. 